\title{
A METHODOLOGICAL FRAMEWORK FOR SUSTAINABILITY RISKS IDENTIFICATION IN THE URBAN WATER SECTOR
}

\author{
M. HEDRICH ${ }^{1}$, M. ELLER ${ }^{2}$ \& A. SONNENBURG ${ }^{2}$ \\ ${ }^{1}$ Chair of Environmental Technology, Institute of Infrastructure and Resources Management, \\ University of Leipzig. \\ ${ }^{2}$ Chair of Water Supply and Groundwater Protection, Institute IWAR, Darmstadt University of Technology.
}

\begin{abstract}
The urban water sector is facing increasing risks associated with climate change, shifting social and economic patterns and regulatory circumstances. The collaborative project 'Sustainability Controlling for Urban Water Systems' (NaCoSi) introduces an innovative approach, which addresses urban water service providers and decision-makers. Various sustainability risks can be identified and controlled to achieve a sustainable urban water management. The starting point is a system of sustainability objectives, which was developed in cooperation with practice partners from the urban water sector. These objectives serve for the operationalization of sustainability within urban water management. A methodological framework for multidimensional risk identification was developed to identify and analyse various sustainability risks. Complex networks of cause-effect relationships are taken apart into unbranched linear causal chains, which are managed as records in a risk database. This paper focuses on the developed methodological framework for sustainability risk identification. In order to understand and handle complex and dynamic cause-effect relationships in urban water systems, diverse sustainability risks were identified and systemized using a causal chain approach. Based on these causal chains, different tools for subsequent risk assessment, monitoring, trend analysis and scenario based simulation games were developed and successfully tested by 12 practice partners.
\end{abstract}

Keywords: causal chain concept, risk assessment, risk identification, sustainability controlling, sustainability objectives, urban water management.

\section{INTRODUCTION}

Urban water systems are facing increasing risks, resulting for example from climate change, institutional change and shifting demographic and economic patterns [1]. Failure of climate change mitigation and water crises are ranked as global most significant long-term risks [2]. The complexity and dynamics of the different changes threaten the economic, ecological and social objectives of urban water systems. Nevertheless, changes and measures are often slow processes, which need long-time periods, and are related to cost intense infrastructure adaption.

In order to meet the challenges of urban water service providers several management instruments are used. Specified management instruments cope with their field of application, but do not focus on threats regarding companies' sustainability objectives. At the moment neither quality management, environmental management nor technical security management, benchmarking nor risk management is capable of systematically identifying and accessing cross-sectional short- and long-term risks [3]. In addition, for urban water systems no methodological frameworks for multidimensional risks identification exist. 
For this purpose, the collaborative project 'Sustainability Controlling for Urban Water Systems' (NaCoSi), which is funded by the German Federal Ministry of Research and Education, developed a risk based sustainability controlling. This management approach allows water service providers and decision-makers to identify and evaluate sustainability risks.

This paper introduces the steps and processes, from which the NaCoSi conceptual framework consists of. It includes the definition of sustainability objectives, the risk analysis, the indicator based monitoring, trend analysis as well as scenario based simulation games and focuses on the methodological framework for risk identification.

\section{SUSTAINABILITY WITHIN URBAN WATER MANAGEMENT}

One of the first steps of the collaborative project was the elaboration of a joint understanding of sustainability for urban water and sewerage service providers. In science and practice, sustainability concepts for urban water systems take multidimensional objective systems as a starting point [4-6]. Partners from technical, economic and socio-ecological research facilities developed together with different practice partners from the German water sector an applicable, common sustainability concept for urban water management and defined a set of sustainability objectives. The systematization of the sustainability objectives was orientated at the five-pillar model of the DVGW (German Technical and Scientific Association for Gas and Water) and the DWA (German Association for Water, Wastewater and Waste) [7]. The long-term perspective together with the intergenerational justice was also used for the understanding of sustainability for urban water management.

\subsection{Sustainability objectives}

The developed multidimensional sustainability objective system is divided into five objective categories: resource use, organisation and technics, employees, corporate responsibility and viability. Every objective category consists of different sustainability objectives for the urban water sector, Fig. 1.

The objective category resource use deals with the responsibility towards the environment. This includes firstly the mandatory tasks of urban water management to protect the environment

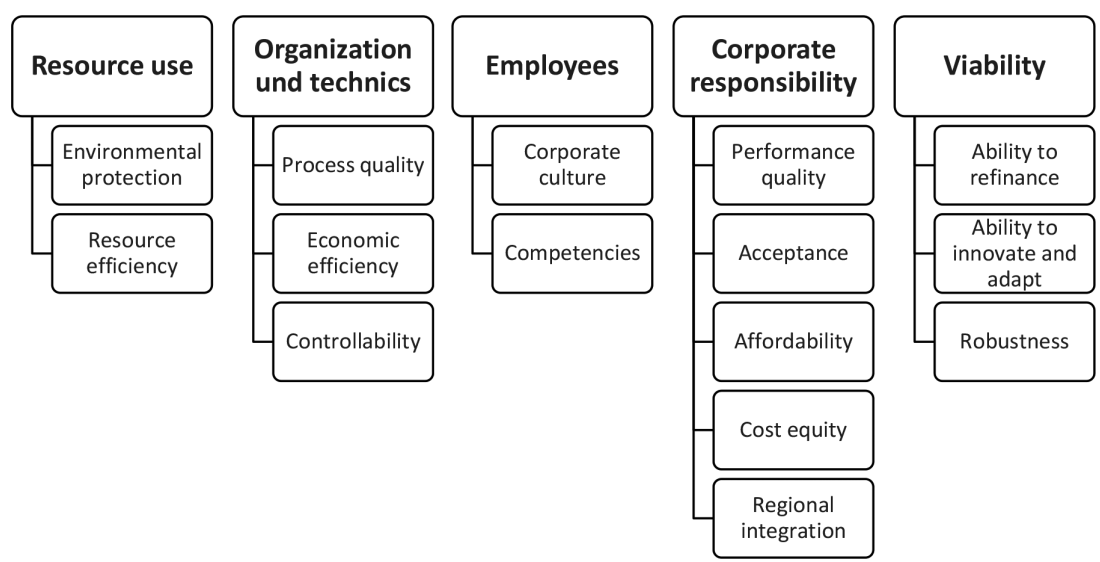

Figure 1: Sustainability objectives for the urban water sector [8]. 
and secondly, more far-reaching aims at efficient resource utilization. Organisation and technics includes sustainability objectives of the company's internal organisational structures as well as the economic and technical implementation of the task fulfilment. The target category employees is concerned with the corporate culture and the competencies of the employees. Urban water systems are part of public services; therefore, companies bear responsibilities for social and economic developments in the region. The corresponding objectives are subsumed under the objective category corporate responsibility. Viability summarizes sustainability objectives, which emphasize the long-term perspective. The abilities to adapt to predictable changes or unforeseen developments are part of this objective category.

The presented objective system can assist the utilities in the achievement of a sustainable urban water management. The joint development by research and practice enables a streamlined implementation and to bridge the gap between academia and practice. Thus, the suggested system has no normative character. Before any implementation is performed, the objective system should be aligned to specific prerequisites.

\subsection{Sustainability risks}

As Lundie et al. [9] state, 'sustainability is not a state to be arrived at but a broad evaluative framework for understanding and justifying social practice'. Sustainable water management is therefore not about achieving an end point but rather the process of influencing thinking and acting of decision-makers and stakeholders [10].

There are many approaches for sustainable urban water management, which intend to reach sustainable conditions by fulfilling sustainability criteria and measure achievement by indicators [6]. The NaCoSi sustainability controlling adopts a different approach: Risk that endanger sustainability objectives are referred to as sustainability risks, which should be managed and minimized in course of the risk management $[11,12]$. By constant control and regulation, a long-term transformation towards sustainable urban water management can be facilitated.

According to ISO 31010 [13] 'the risk management process aids decision making by taking account of uncertainty and the possibility of future events or circumstances (intended or unintended) and their effects on agreed objectives'. In case that companies will not achieve their sustainability objectives, their sustainable performance is endangered. Therefore, sustainability risks result from missing the described sustainability objectives.

\subsection{Conceptual framework for sustainability controlling}

The developed $\mathrm{NaCoSi}$ tools consist of a monitoring and a risk assessment, which analyse, evaluate and visualize sustainability risks. Therefore, a risk database is used to interrogate entrepreneurial information regarding sustainability risks. Risks can be calculated, aggregated and assigned to different sustainability objectives. Indicators, which measure the effects of risks, are aligned to boundary values and with the help of indicator time series a trend analysis is conducted. The results from the risk analysis and the monitoring tools are used to compare subjective and objective data in order to validate the different risks. The NaCoSi sustainability controlling was successfully tested and applied by 12 practice partners.

The developed conceptual framework for sustainability controlling consists of different steps, Fig. 2. 


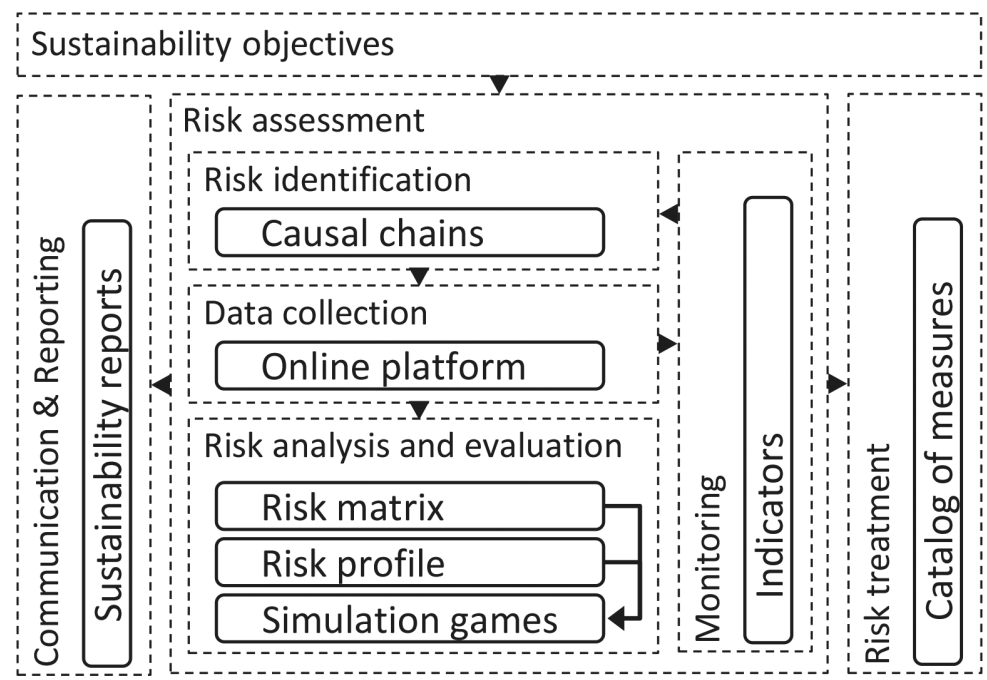

Figure 2: NaCoSi sustainability controlling conceptual framework.

In order to implement the $\mathrm{NaCoSi}$ sustainability controlling, sustainability objectives must be defined. The next step risk assessment consists of four processes: the risk identification, the data collection, the risk analysis and the monitoring. The risk identification is based on the causal chain concept and is the fundament of the NaCoSi sustainability controlling (chapter 3). In the process of the data collection an online questionnaire for risk and indicators is deviated from the causal chains. The last two processes of the risk assessment are the risk analysis and evaluation and monitoring, which process the collected data.

Within the risk analysis and evaluation, the risk profile has a cockpit function, where all risks - aggregated over their objective categories - are depicted. It gives an overview of vulnerable objectives and the risk distribution. The highest risk, the lowest risk and the median are indicated. Every objective category is represented by a risk matrix, which shows the consequence of loss and the probability of occurrence. Together with a table of the objective category all details of the risks are available, such as the cause and effect of the risk or the affected sustainability objective. Risks can now be analysed and evaluated. Based on indicators from the data collection a monitoring can be performed and aligned to boundary values, which can be derived by legal limits and expert knowledge. Trend analysis can be conducted with indicator time series. With the help of indicator tendencies sustainability risks can be validated. The last two steps of conceptual framework for sustainability controlling are the communication and reporting and the risk treatment. The communication and reporting is a result of the risk assessment and consist of sustainability reports regarding entrepreneurially sustainability risks. Based on the information of these reports and on simulation games strategies can be developed to avoid or exit different future worst-case scenarios. With the help of simulation games and as a second result of the risk assessment, a catalog of measures for risk treatment can be developed.

The core of the new developed sustainability controlling is the risk identification. Its adaptable architecture enables different analysis tools and has the potential for other fields of applications. 


\section{RISK IDENTIFICATION BY CAUSAL CHAINS}

Water systems may be considered as complex socio-technic and socio-economic systems. As Pahl-Wostl [14] states, 'it has become increasingly clear that the pressing problems in this field have to be tackled from an integrated perspective taking into account environmental, human and technological factors and in particular their interdependence'. The risk environment of water systems is therefore very polymorph. Cause and effect relations form complex networks. For the sustainability controlling a method for risk identification is needed, which allows the diverse risk factors and risk pathways to be systematically gathered, in order to make them accessible for a subsequent risk analysis. Standard problem-solving approaches of risk management (e.g. ISO 31010 [13]) rapidly lose their effectiveness, when facing complex cause and effect relations. Hence, an integrated approach has been developed that allows to initially regard single, isolated risks and afterwards to picture and analyse complex risk networks [15]. Instead of trying to capture complex networks on the whole, unbranched, linear causal chains are collected, which are managed as records in a risk database. As a result, a straight-line modular system is formed to model relationships between causes and respective affected sustainability objectives. Thus, each causal chain describes one isolated sustainability risk and consists of determined consecutive elements, which are described below, Fig. 3.

The elements cause, consequence and sustainability objective constitute the core components of each causal chain, whereas the other elements and categories provide supplemental information and allow to refine the subsequent risk analysis.

The risk source triggers the cause of a sustainability risk and thus is causally prior to the risk's cause. It provides additional information about the origin and character of the risk and thereby helps to specify the cause category.

As causality may be gradually traced back infinitely, the cause of a sustainability risk is defined as the last event of a sequence of causal events that directly draws an impact on the urban water system. Referred to the system boundaries, causes can be of external or internal origin. For further systematization and subsequent identification of possible problem areas, each cause is assigned to a cause category, Table 1.

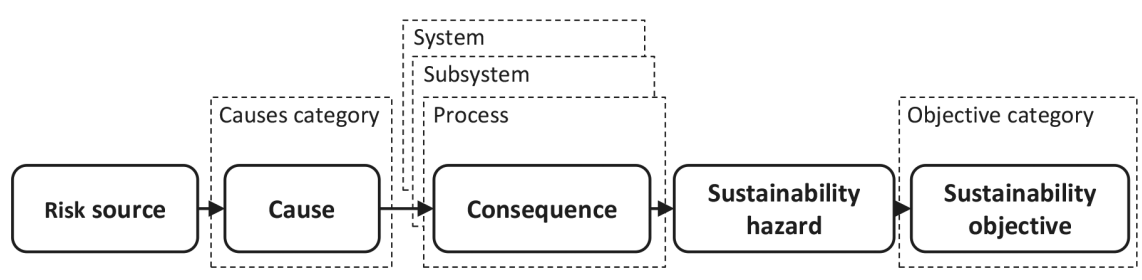

Figure 3: NaCoSi causal chain scheme.

Table 1: Cause categories.

\begin{tabular}{ll}
\hline Cause category & Example for related cause \\
\hline Society & Population decrease \\
Legislation & Increasing legal requirements \\
Organisation & Bad planning \\
Technology & Technological failures \\
\hline Environment & Increasing torrential rainfall \\
\hline
\end{tabular}




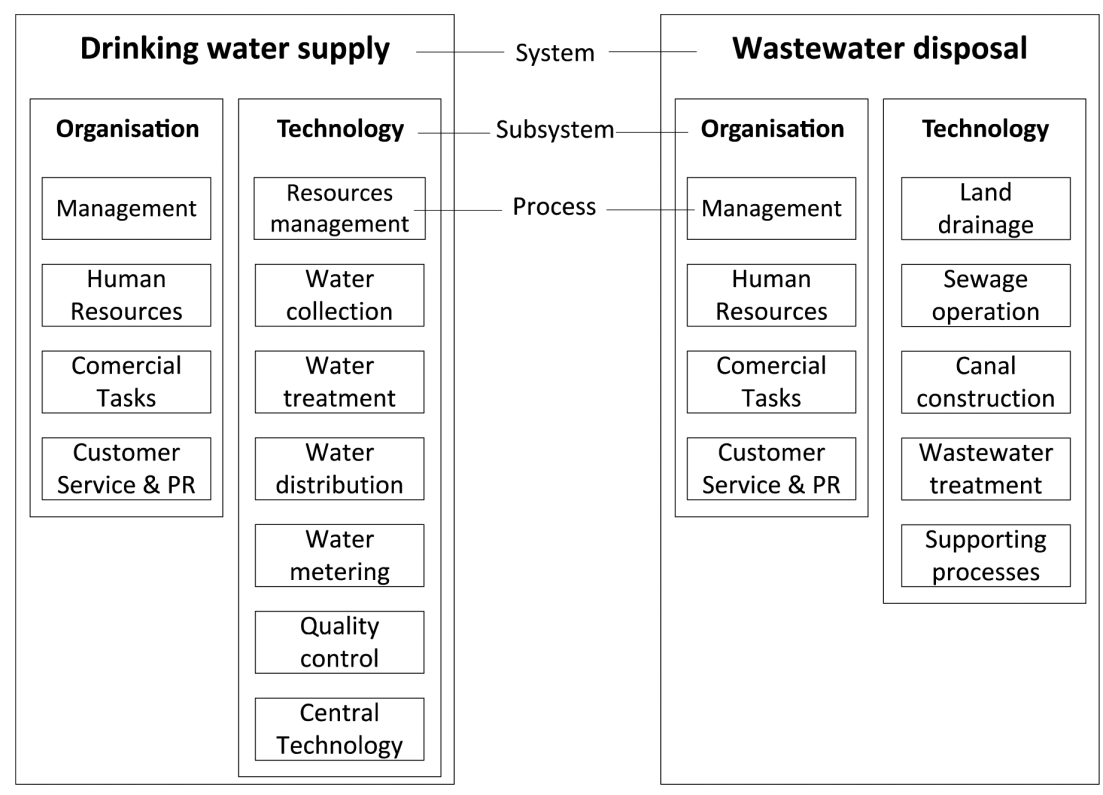

Figure 4: Hierarchical process model of urban water systems.

The consequence is defined as an observable effect of a related cause within the urban water system. In order to further specify the point of action, a comprehensive hierarchical process model is applied, which considers all processes of the urban water system from catchment to consumer and vice versa, Fig. 4 . The entirety of the processes constitutes the considered functional system boundaries.

The sustainability hazard specifies why and how exactly the corresponding sustainability objective is affected. It can constitute a threshold after which a consequence becomes effectual. As the last element of each causal chain the affected sustainability objective, as described above (chapter 2.1), is addressed.

\subsection{Analysing causal networks}

As a result of the risk identification process by causal chains, an extensive risk database can be compiled, which serves for the subsequent in-depth risk analysis. By re-combining the straight line causal chains, even complex cause-effect networks can now be delineated and reveal the interconnections of sustainability risks, Fig. 5.

Applying network analysis methods or classification rules, it can be analysed whether a certain cause affects several sustainability objectives or whether a sustainability objective is affected by various causes. Thereby combined causes can strengthen or attenuating affected risks. Severe risk factors, vulnerable processes and sustainability goals can thus be identified. In the given example causal network in Fig. 5

- One cause may trigger multiple consequences (cause 1 triggers consequence 1 to 3 ) and subsequently affects 3 sustainability objectives (sustainability objective 1 to 3 ).

- One consequence may have multiple causes (consequence 2 is triggered by cause 1 to 3 ). 


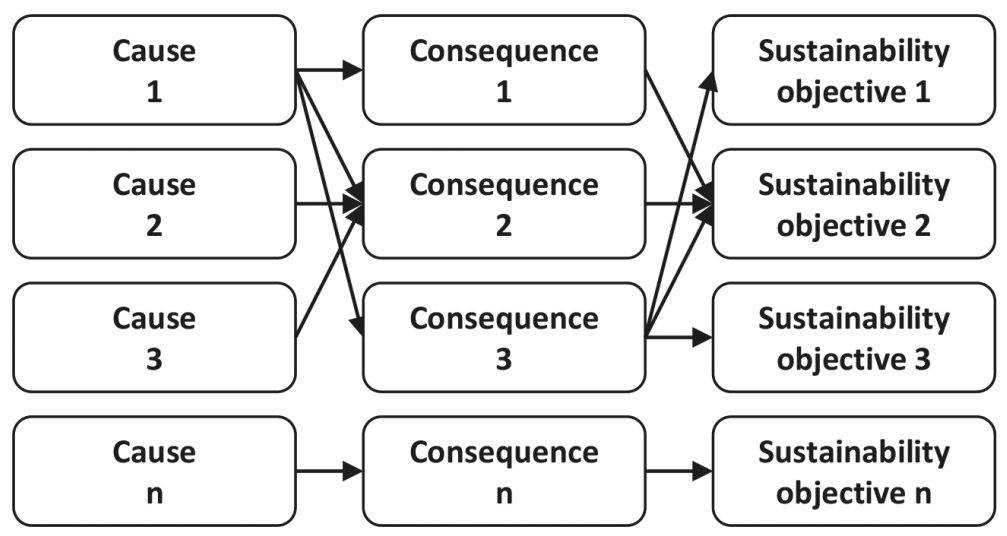

Figure 5: Example causal network (simplified causal chains).

- One consequence may affect multiple sustainability objectives (consequence 3 affects sustainability objective 1 to 3 ).

- One sustainability objective may be affected by multiple consequences and their corresponding precedent causes (sustainability objective 2 is affected by consequence 1 to 3 and the precedent causes 1 to 3 ).

This information can be used for the following risk prevention and treatment. For instance, for the purpose of risk avoidance the most potent cause 1 could be tried to be eliminated. As risk reduction measure, consequence 2 could be muted because it is triggered by multiple causes or consequence 3 could be muted as it affects multiple sustainability objectives. Since the consequence is associated with a specific process of the urban water system, as described above, it is also possible to identify the most vulnerable processes to raise their robustness.

\section{CONCLUSION}

The NaCoSi sustainability controlling is a risk and indicator based method, which allows risk identification, analysis, validation and allows the derivation of measures to reduce sustainability risks in urban water systems. It will help urban water service providers to identify and assess their specific sustainability risk situation and depict sustainability risk profiles.

The controlling proved the functionality successfully by 12 practice partner, produced specific sustainability reports and derived a catalog of measures to avoid sustainability risks. The development of the $\mathrm{NaCoSi}$ sustainability controlling generates a conceptual framework. Within this conceptual framework different steps and processes are defined, delimited and described. Sustainability objectives for urban water management have been evolved. A risk assessment has been developed, which consist of risk identification, data collection, risk analysis and evaluation and monitoring.

The methodological framework for sustainability risk identification is the centre of the conceptual framework for the $\mathrm{NaCoSi}$ sustainability controlling and the focus of this paper. It allows the systematically identification of sustainability risks by the help of the causal chain concept. The causal chains are collected in a risk database. By means of different systematization options of the risk database, vulnerable processes, potent risks and especially endangered sustainability objectives can be spotted. It could be shown that the adaptable 
architecture provides a versatile basis for risk analysis and has the potential for further developments like network analysis.

The objective to support the companies on their way to a long-term sustainable performance and to minimize the complexity of multidimensional, interrelated sustainability risks has been achieved. Because of synergy effects from existing management approaches, urban water management has an easy and adaptable access to the $\mathrm{NaCoSi}$ sustainability controlling.

\section{ACKNOWLEDGEMENTS}

The research for this paper was carried out as part of the collaborative project 'Sustainability Controlling for Urban Water Systems' (NaCoSi), as part of the research program 'Smart and Multifunctional Infrastructural Systems for Sustainable Water Supply, Sanitation and Stormwater Management' (INIS), funded by the German Federal Ministry of Research and Education. The authors would like to thank the research partners and to acknowledge the valuable contribution of the eleven water and sewerage service provider participating as industry partners.

\section{REFERENCES}

[1] United Nations Environment Programme, Sustainable, resource efficient cities- Making it happen, South Africa, 2012.

[2] World Economic Forum, Global risk report 2016, Geneva, 2016.

[3] Beck, J., Eller, M., Geyler, S., Hedrich, M., Holländer, R., Jansky, N., Kerber, H., Krause, S., Lux, A., Möller, K., Sonnenburg, A., Tocha, C. \& Urban, W., Nachhaltigkeitscontrolling in der Siedlungswasserwirtschaft. DVGW Energie Wasser Praxis, 66(4), pp. 28-30, 2015.

[4] Kahlenborn, W. \& Kraemer, A., Nachhaltige Wasserwirtschaft in Deutschland. Umweltbundesamt: Berlin, 1999.

http://dx.doi.org/10.1007/978-3-642-58511-1

[5] Palme, U. \& Tillman, A.M., Sustainable urban water systems in indicators: researchers' recommendations versus practice in Swedish utilities. Water Policy, 11(2), pp. 250 268, 2009. http://dx.doi.org/10.2166/wp.2009.013

[6] Marques, R.C., da Cruz, N.F. \& Pires, J., Measuring the sustainability of urban water services. Environmental Science \& Policy, 54, pp. 142-151, 2015. http://dx.doi.org/10.1016/j.envsci.2015.07.003

[7] DVGW W 1000, Anforderungen an die Qualifikation und die Organisation von Trinkwasserversorgern, DVGW, Bonn, 2004.

[8] Eller, M., Geyler, S., Jansky, N., Kerber, H., Lux, A., Möller, K., Perz, A., Rüger, J., Sonnenburg, A. \& Tocha, C., Nachhaltigkeitsziele und Risiken für siedlungswasserwirtschaftliche Unternehmen: erste Bausteine für ein Nachhaltigkeitscontrolling. ISOE-Diskussionspapiere, 37, 2014.

[9] Lundie, S., Asholt, N. \& Livingston, D., Methodology for Evaluating the Overall Sustainability of Urban Water Systems: Sustainability Framework. Centre for Water and Waste Technology, University of New South Wales, 2005.

[10] Pearson, L.J., Coggan, A., Proctor, W. \& Smith, T.F., A sustainable decision support framework for urban water management. Water Resources Management, 24(2), pp. 285-301, 2009. 
[11] Benz, P., Konzept zum Nachhaltigkeitscontrolling in der Siedlungswasserwirtschaft. Dissertation, Institute IWAR, Technische Universität Darmstadt, 2014.

[12] ISO 31000:2009, Risk management.

[13] ISO 31010:2009, Risk management - Risk assessment techniques.

[14] Pahl-Wostl, C., Transitions towards adaptive management of water facing climate and global change. Water Resources Management, 21(1), pp. 49-62, 2006. http://dx.doi.org/10.1007/s11269-006-9040-4

[15] Geyler, S., Lux, A., Möller, K., Tocha, C., Hedrich, M., Sonnenburg, A., Beck, J., Eller, M., Jansky, N., Kerber, H., Holländer, R., Krause, S. \& Urban, W., Sustainability controlling for urban water systems. Proceeding of the Cities of the Future Conference Transitions to the Urban Water Services of Tomorrow (TRUST). Mülheim an der Ruhr, pp. 205-211, 2015. 